\title{
Evaluation of Three Planetary Boundary Layer Schemes in the WRF Model
}

\author{
XIAO-MING HU \\ Department of Atmospheric Sciences, Texas A\&M University, College Station, Texas, and Department of Meteorology, \\ The Pennsylvania State University, University Park, Pennsylvania \\ JOHN W. NIELSEN-GAMMON \\ Department of Atmospheric Sciences, Texas A\&M University, College Station, Texas
}

FUQING ZHANG

Department of Meteorology, The Pennsylvania State University, University Park, Pennsylvania

(Manuscript received 5 November 2009, in final form 14 April 2010)

\begin{abstract}
Accurate depiction of meteorological conditions, especially within the planetary boundary layer (PBL), is important for air pollution modeling, and PBL parameterization schemes play a critical role in simulating the boundary layer. This study examines the sensitivity of the performance of the Weather Research and Forecast (WRF) model to the use of three different PBL schemes [Mellor-Yamada-Janjic (MYJ), Yonsei University (YSU), and the asymmetric convective model, version 2 (ACM2)]. Comparison of surface and boundary layer observations with 92 sets of daily, 36-h high-resolution WRF simulations with different schemes over Texas in July-September 2005 shows that the simulations with the YSU and ACM2 schemes give much less bias than with the MYJ scheme. Simulations with the MYJ scheme, the only local closure scheme of the three, produced the coldest and moistest biases in the PBL. The differences among the schemes are found to be due predominantly to differences in vertical mixing strength and entrainment of air from above the PBL. A sensitivity experiment with the ACM2 scheme confirms this diagnosis.
\end{abstract}

\section{Introduction}

Southeast Texas, especially the Houston-Galveston area, frequently exceeds the National Ambient Air Quality Standard (NAAQS) for ozone (Langford et al. 2009). Accurately simulating the meteorological processes within the planetary boundary layer (PBL) is critical for correctly simulating pollution events in this area (Daum et al. 2003; Banta et al. 2005; Zhang et al. 2007). Different PBL schemes adopt different assumptions regarding the transport of mass, moisture, and energy, which may lead to differences in the boundary layer and subsequently the whole model domain. PBL schemes have been extensively evaluated and intercompared in the framework of the fifth-generation Pennsylvania State

Corresponding author address: Dr. Fuqing Zhang, Dept. of Meteorology, The Pennsylvania State University, University Park, PA 16802.

E-mail: fzhang@psu.edu
University-National Center for Atmospheric Research Mesoscale Model (MM5; Braun and Tao 2000; Bright and Mullen 2002; Zhang and Zheng 2004; Zhong et al. 2007; Srinivas et al. 2007; Miao et al. 2008; Han et al. 2008). A few recent studies also examined the sensitivity of next-generation Weather Research and Forecast (WRF) model predictions to PBL schemes (Misenis et al. 2006; Jankov et al. 2005, 2007; Li and Pu 2008; Borge et al. 2008). However, none of these studies attempted to attribute the root causes of model performance differences to the different assumptions in each scheme. Moreover, there has been an important recent change to the Yonsei University (YSU) scheme (Hong et al. 2006) in WRF (Hong and Kim 2008), and a new PBL scheme, the asymmetric convective model, version 2, (ACM2) scheme (Pleim 2007a) has been added to WRF. The performance of the ACM2 scheme and the updated YSU scheme in the WRF model needs to be evaluated.

In this study WRF, version 3.0.1, is used to simulate the meteorological conditions of the Texas region in 
summer 2005, during the Second Texas Air Quality Study (TexAQS2; Parrish et al. 2009). Observations collected during TexAQS2 provide a comprehensive validation dataset for model experiments. The sensitivities of the WRF simulations to the use of two frequently used PBL schemes, the YSU scheme and the Mellor-YamadaJanjic (MYJ) scheme, as well as the recently added ACM2 scheme, are examined. We identify differences in model performances with possible consequences for air quality simulations and seek causes of those differences.

\section{Description of the three PBL schemes}

PBL schemes are used to parameterize the unresolved turbulent vertical fluxes of heat, momentum, and constituents such as moisture within the planetary boundary layer and throughout the atmosphere. A closure scheme is needed to obtain turbulent fluxes from mean quantities (Holt and Raman 1988). One type of closure scheme estimates the turbulent fluxes at each point in model grids from the mean atmospheric variables and/or their gradients at that point. This is called local closure. The assumption that fluxes depend solely on local values and gradients of basic model variables is least valid under convective conditions when turbulent fluxes are dominated by large eddies that transport fluid longer distances (Troen and Mahrt 1986; Stull 1984). Nonlocal fluxes may be included as a parameterized nonlocal term (Troen and Mahrt 1986; Noh et al. 2003) or treated explicitly (Stull 1984; Blackadar 1978; Zhang and Anthes 1982; Pleim and Chang 1992). Among the three PBL schemes that will be evaluated in this study, the MYJ scheme is a local closure model, while the YSU and ACM2 schemes are nonlocal models. The YSU scheme considers the nonlocal fluxes implicitly through a parameterized nonlocal term (Hong et al. 2006) and the ACM2 scheme considers them explicitly through a transilient term (Pleim and Chang 1992).

The MYJ PBL scheme uses the 1.5-order (level 2.5) turbulence closure model of Mellor and Yamada (1982) to represent turbulence above the surface layer (Janjic 1990, 1994, 2001). The MYJ scheme determines eddy diffusion coefficients from prognostically calculated turbulent kinetic energy (TKE). Mellor and Yamada (1982) argue that the scheme is appropriate for all stable and slightly unstable flows, but that errors are more likely as the flow approaches the free-convection limit.

The YSU PBL scheme (Hong et al. 2006) is a firstorder nonlocal scheme, with a countergradient term in the eddy-diffusion equation. The YSU scheme is modified in WRF version 3 from the Hong et al. (2006) formulation by increasing the critical bulk Richardson number from zero to 0.25 over land, thereby enhancing mixing in the stable boundary layer (Hong and Kim 2008).
The ACM2 PBL scheme (Pleim 2007a,b) includes a first-order eddy-diffusion component in addition to the explicit nonlocal transport of the original ACM1 scheme (Pleim and Chang 1992). This modification is designed to improve the shape of vertical profiles near the surface. For stable or neutral conditions, the ACM2 scheme shuts off nonlocal transport and uses local closure.

\section{WRF model simulations with the three PBL schemes}

\section{a. Description of model configuration and evaluation data}

Four model domains with two-way nesting are used (Fig. 1) with grid spacings of 108, 36, 12, and $4 \mathrm{~km}$. The $12-\mathrm{km}$ domain covers most of the south-central United States, and the 4-km domain covers eastern Texas, western Louisiana, and part of Arkansas. All model domains have 43 vertical layers, and the model top is set at $50 \mathrm{hPa}$. The lowest model sigma levels are at 1.0, 0.996, 0.99, $0.98,0.97,0.96,0.95,0.94,0.93,0.92,0.91,0.895,0.88$, $0.865,0.85,0.825$, and 0.80 . The physical parameterization schemes used in all model domains include Dudhia shortwave radiation (Dudhia 1989), rapid radiative transfer model (RRTM) longwave radiation (Mlawer et al. 1997), WRF Single-Moment 6-Class (WSM6) microphysics (Hong et al. 2004), and the Noah land surface scheme (Chen and Dudhia 2001). A cumulus scheme is not used on the 12- or 4-km fine domains while the 108- and 36-km domains use the Grell-Dévényi ensemble scheme (Grell and Dévényi 2002). We also tested the use of the GrellDévényi ensemble scheme on the $12-\mathrm{km}$ domain and found very little effect on the relative biases of meteorological variables predicted using the three PBL schemes, while the agreement with observations of predictions using the individual PBL schemes changed slightly. The National Centers for Environmental Prediction (NCEP) global forecast system (GFS) final (FNL) operational global analyses are used for initial conditions (for both the atmosphere and the soil) and boundary conditions.

Three 36-h forecasts, one for each PBL scheme being tested, are initiated at 0000 UTC (1800 CST) every day from 1 July to 30 September 2005. The simulations with the YSU and ACM2 schemes use the Monin-Obukhov surface layer scheme while the simulations with the MYJ scheme use the Janjic Eta Monin-Obukhov surface layer scheme. ${ }^{1}$ The first $12 \mathrm{~h}$ of each simulation are

\footnotetext{
${ }^{1}$ In the WRF model, some PBL schemes are tied to particular surface layer schemes (Skamarock et al. 2008), so a single common surface layer scheme could not be used here.
} 


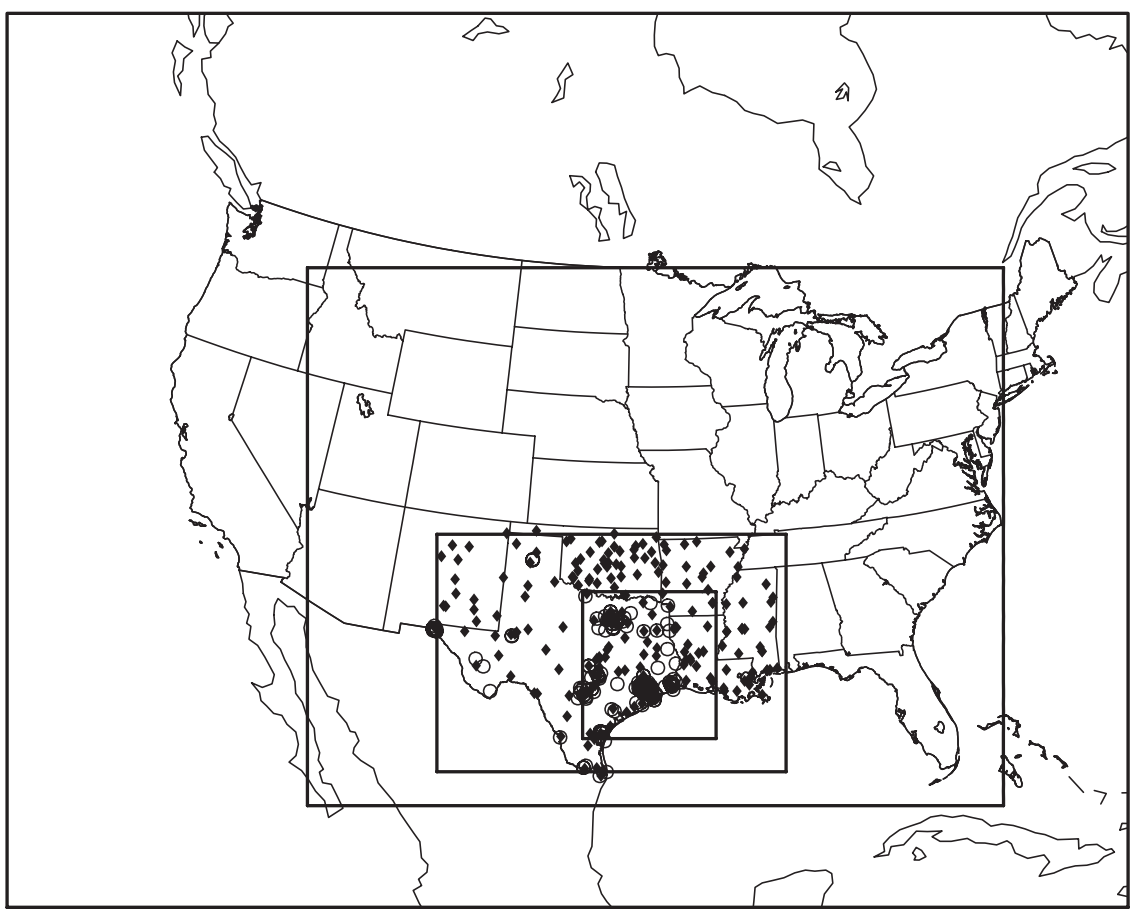

FIG. 1. Map of model domains and locations of TCEQ (circles) and NWS-FAA (diamonds) observation sites.

treated as spinup, and the remaining $24 \mathrm{~h}$ (from 0700 to 0700 CST) are used for evaluation.

Data for model validation includes surface observations at National Weather Service (NWS) and Federal Aviation Administration (FAA) sites and at Texas Commission on Environmental Quality (TCEQ) sites, aircraft data from the Aircraft Communications Addressing and Reporting System (ACARS), and mixing heights estimated from radar wind profilers. The locations of the TCEQ and NWS-FAA sites are also shown in Fig. 1. Evaluations will focus on the 12-km domain, which incorporates information from the $4-\mathrm{km}$ domain through two-way nesting.

\section{b. Model results and evaluation}

Figure 2 shows the three-month (July-September) mean diurnal variation of 2-m temperature and dewpoint at the 211 NWS-FAA sites. The dewpoint at $2 \mathrm{~m}$ is diagnosed from the water vapor mixing ratio at $2 \mathrm{~m}$ and the surface pressure for comparison with observations. In the morning and midday (from 0800 to 1400 CST), the temperatures produced with the three schemes are similar. During this period all sets of runs show negative biases and the biases expand with time to around $-2^{\circ} \mathrm{C}$. In the afternoon, the temperatures predicted with the MYJ scheme are lower than those predicted with YSU and ACM2, and the cold biases persist. Cold biases have previously been reported from simulations over southeastern Texas in the fall using the MM5 model with the MYJ scheme (Bao et al. 2005; Zhong et al. 2007) and using the WRF model with chemistry and the YSU scheme (Wilczak et al. 2009). After sunset, YSU runs produce higher temperatures (thus less temperature bias) than
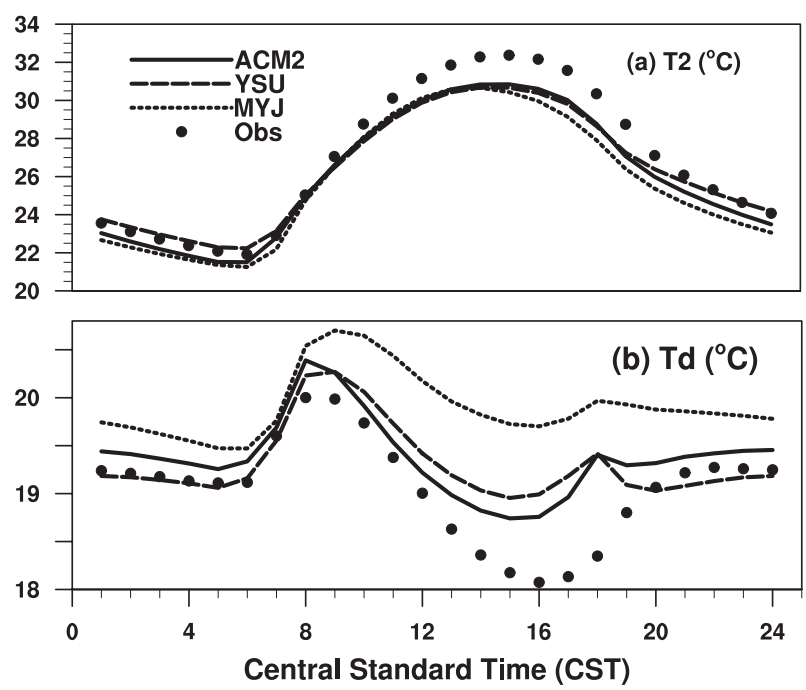

FIG. 2. Mean diurnal variation of 2-m (top) temperature and (bottom) dewpoint at 211 NWS-FAA sites throughout the 3-month simulation period. 


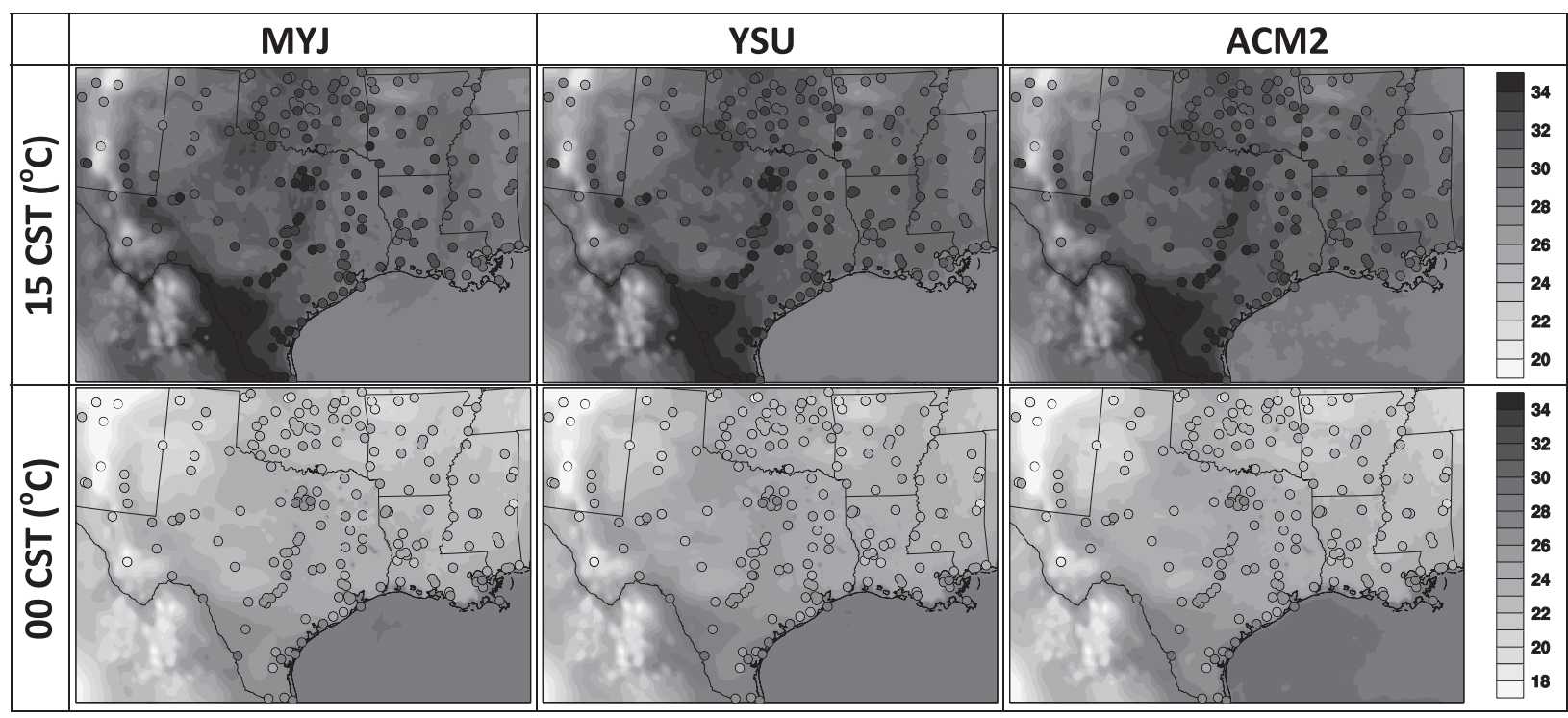

FIG. 3. Three-month mean 2-m temperature at (top) 1500 and (bottom) 0000 CST predicted using (left to right) 3 PBL schemes. The observed values at NWS-FAA sites are indicated by shaded circles.

runs with MYJ or ACM2, with MYJ temperatures the lowest (Fig. 2a). Overall for the full diurnal cycle the mean biases of $\mathrm{T} 2$ predicted by the WRF model with the MYJ, YSU, and ACM2 schemes are $-1.25,-0.63$, and $-0.9^{\circ} \mathrm{C}$, respectively. The dewpoint is overpredicted with MYJ at all hours with a mean bias of $0.86^{\circ} \mathrm{C}$, while at night, the YSU runs tend to produce the lowest dewpoints (Fig. 2b).

The WRF thermodynamic variables are not directly simulated at $2 \mathrm{~m}$, but instead are diagnosed from values at the land surface and the lowest model layers. Errors in this diagnosis of the vertical transition from surface to atmospheric values could lead to fictitious biases when compared to observations. For example, a daytime cold bias could be caused by an underestimate in the depth of the superadiabatic layer near the ground, but such an error should also lead to a dry bias since both heat and moisture fluxes are typically upward. The opposite sign of the daytime temperature and dewpoint biases suggests that the biases are largely caused by physical processes simulated by the model and not merely because of an error in diagnosing 2-m values.

Figure 3 shows the spatial distribution of the 3 -month mean 2-m temperature (T2) at 1500 and 0000 CST predicted using the three different PBL schemes. Observations from the NWS-FAA sites are also shown for comparison. At 1500 CST, the temperature over eastern Texas, Louisiana, and Mississippi is underpredicted with the MYJ scheme. The model runs with YSU and ACM2 predict higher temperatures over those areas, thus showing better agreement with observations. At $0000 \mathrm{CST}$, the
MYJ and ACM2 runs underpredict the temperature over the area from Dallas to San Antonio. The YSU runs, predicting higher temperatures, have the smallest bias in the Dallas-San Antonio area, but produce temperatures that are too high over western Oklahoma. The differences among the three PBL schemes seen in Fig. 3; that is, the YSU and ACM2 runs predict higher temperatures during afternoon than the MYJ runs, while the YSU runs predict higher temperatures than the ACM2 and MYJ runs during nighttime, are consistent with those seen in Fig. 2.

Mean time series of simulated and observed temperature and dewpoint at $2 \mathrm{~m}$ over the 171 TCEQ sites for 26 July-8 August 2005, a period of interest for its high levels of air pollution, are displayed in Fig. 4. The TCEQ sites are concentrated in the metropolitan areas such as Houston and Dallas-Fort Worth. The mean biases seen in Figs. 2-3 are also apparent nearly every day in Fig. 4. At these urban sites, all runs, even with YSU, produce temperatures that are lower than observed at night. During daytime, the maximum temperature error varies from day to day, with very little error on 27 and 30 July and 5 August, but with more substantial cold biases on 31 July and 1, 6, and 7 August. This suggests that some of the daytime temperature biases may be caused by errors in cloud cover and/or soil moisture. However, our focus here is not to diagnose mean model biases but rather differences in biases among the three PBL schemes. All three sets of runs overestimate the dewpoint most of the time, but those with MYJ produce the highest values (Fig. 4b). 

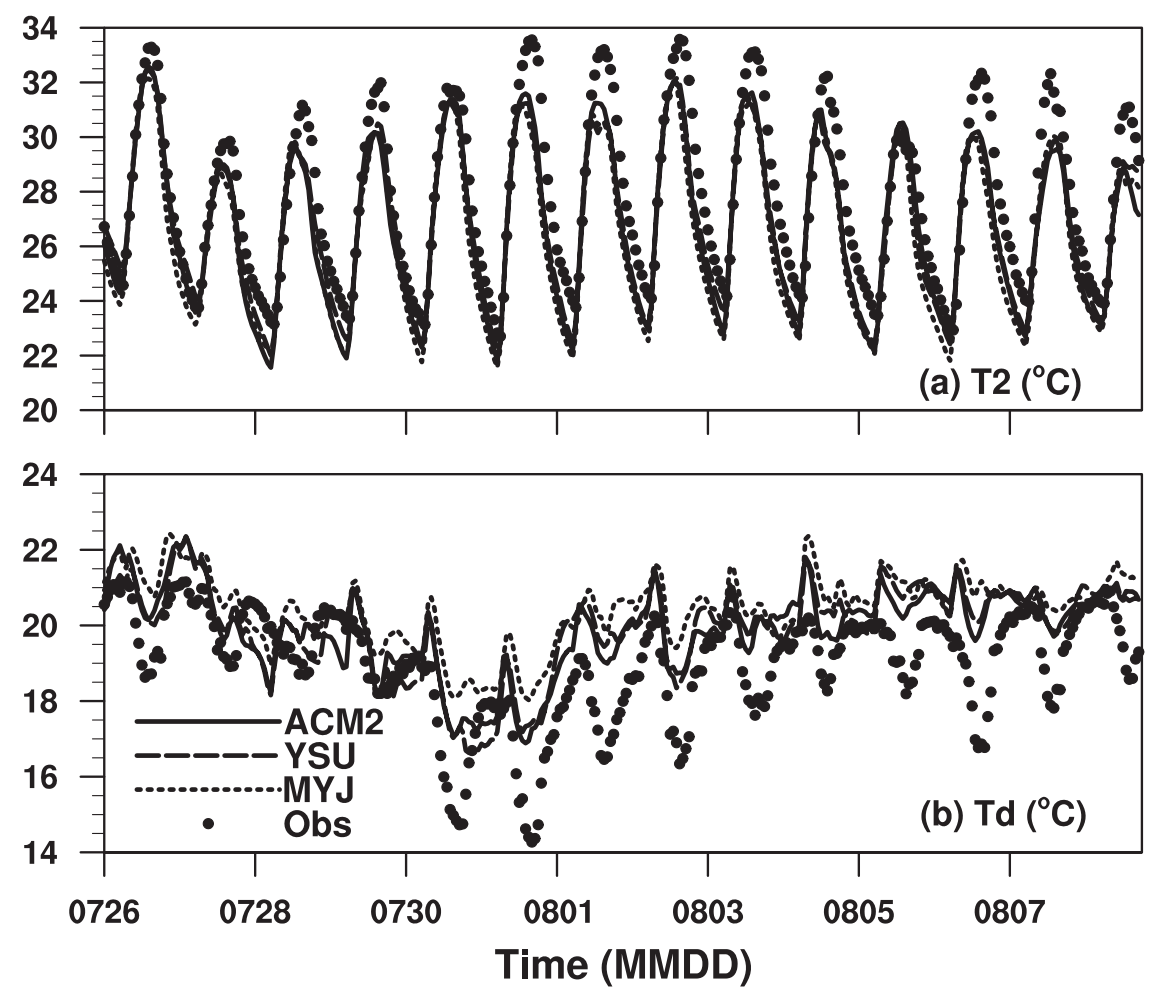

FIG. 4. Comparison of mean time series of (top) temperature and (bottom) dewpoint at $2 \mathrm{~m}$ with mean observations at TCEQ sites for $26 \mathrm{Jul}-8$ Aug.

One possible cause of the lower temperatures produced with MYJ would be a difference in the heat fluxes delivered by the Janjic Eta Monin-Obukhov surface layer scheme (used with MYJ) when compared with those delivered by the Monin-Obukhov surface layer scheme (used with YSU and ACM2). To check this possibility, the mean sensible heat fluxes (HFX) are shown in Figs. 5a and 6a for comparison with Figs. 2 and 4. Instead of smaller HFX in the MYJ simulations, Fig. 5a shows that the HFX is larger than in the YSU and ACM2 simulations during daytime averaged over the NWS-FAA sites and no consistent differences of HFX are found from day to day at the TCEQ sites (Fig. 6a). This is further illustrated in Fig. 6b, which shows the difference of T2 and HFX over the TCEQ sites between simulations with the YSU and MYJ schemes for the period of 26 July8 August. YSU predicts higher T2 but lower HFX than MYJ during most hours. During the period of 1500 2000 CST (shaded in Fig. 6b), the difference of T2 between YSU and MYJ become prominent. During these hours, the higher T2 predicted by YSU is not attributable to higher HFX (Fig. 6b).

Another aspect of the performance of the surface layer schemes is the Bowen ratio, the ratio of surface HFX to latent heat flux (LH). Thus in addition to the
HFX, the mean diurnal variations of $\mathrm{LH}$ and Bowen ratio at NWS-FAA sites are shown in Fig. 5. During daytime (0600-1800 CST), the model runs with the Janjic Eta surface layer scheme have a slightly higher Bowen ratio than runs with YSU and ACM2. A higher Bowen ratio is shown to be partially responsible for a warmer and drier climate in regional climate simulations (Leung and Ghan 1998). Thus the higher Bowen ratio cannot explain the colder and moister PBL predicted by the MYJ runs. Instead, it seems likely that the cooler conditions associated with the MYJ PBL scheme, by enhancing the landair temperature difference, causes the surface layer scheme to respond with larger HFX.

Incoming solar radiation was also compared among the schemes and against observations at certain TCEQ sites, as a check for possible differences caused by cloud cover. Simulations with both MYJ and YSU produced incoming solar radiation slightly smaller that what was observed, while the solar radiation with the ACM2 scheme was slightly higher than what was observed (not shown). Collectively, the comparisons of HFX, LH, and incoming solar radiation suggest that the differences in performance between different schemes likely arise directly within the PBL schemes themselves, instead of differences in the surface-layer schemes (surface heat 

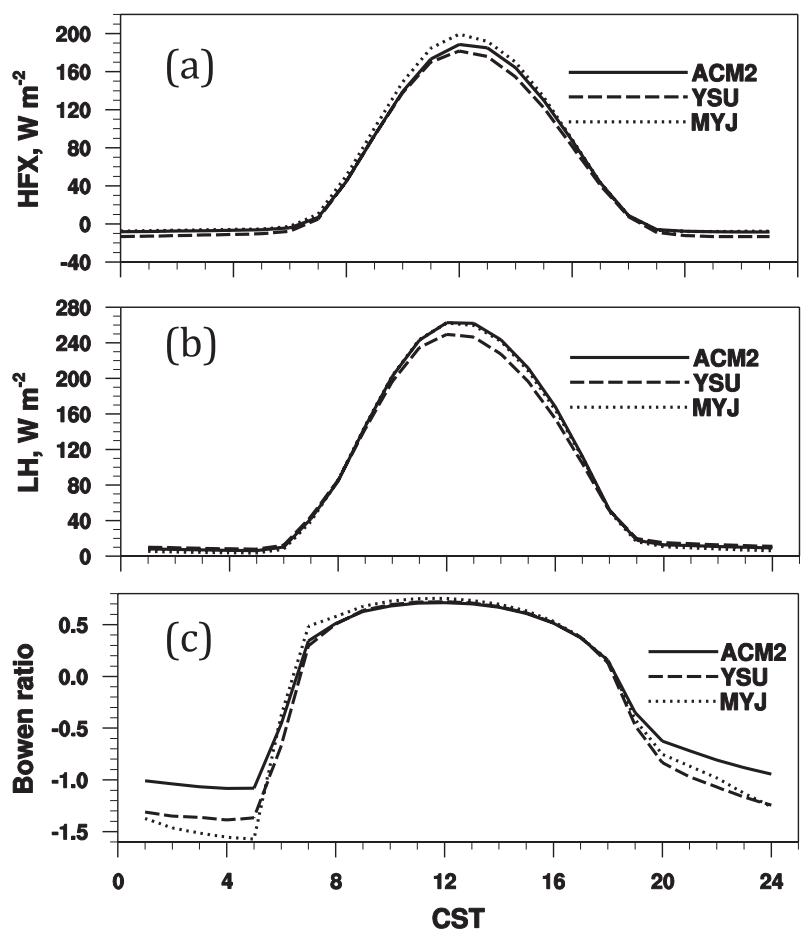

FIG. 5. Mean diurnal variation of (a) surface sensible HFX, (b) LH, and (c) Bowen ratio at 211 NWS-FAA sites for all three months.

fluxes) or partially external feedback mechanisms such as changes in cloud cover.

MYJ is a local closure PBL scheme. Local closure schemes are reported to produce insufficient mixing in the convective boundary layer (Brown 1996). Weaker vertical mixing would transfer less surface water vapor to higher layers. This is consistent with previous studies showing that the output of the MYJ scheme was too moist near the surface (Bright and Mullen 2002; Jankov et al. 2007). However, weaker vertical mixing would also transfer less heat from the surface to higher layers during the day. If the difference between the schemes were solely caused by mixing within the lowest levels of the atmosphere, the scheme that produces the moistest daytime surface conditions (MYJ) should also produce the warmest daytime surface conditions, but it does not.

The other source of air with differing thermodynamic characteristics is air entrained through the top of the PBL. While air originating from the surface layer during the daytime typically has both higher potential temperature and greater moisture than the average air within the PBL, air entrained from above the PBL has higher potential temperature but less moisture than typical PBL air. Consequently, errors in entrainment would lead to oppositely signed biases in PBL temperature and dewpoint. If caused by entrainment, the biases imply weaker entrainment in the MYJ simulations than in the YSU and ACM2 simulations.

Differences in vertical mixing and entrainment would create differences in the vertical development of the PBL. The PBL height is an important variable for air quality modeling, which is often difficult to simulate accurately in numerical models (Dabberdt et al. 2004). ${ }^{2}$ Figure 7 compares the 3-month mean diurnal variations of the simulated PBL heights with the PBL heights estimated from radar wind profiler data at eight sites. The PBL height estimates from the eight radar wind profilers are available hourly but with occasional missing reports (Nielsen-Gammon et al. 2008); the simulated PBL heights are extracted only when observations are available. The period of 23-25 September coincided with the passage of Hurricane Rita through eastern Texas and is excluded. The observed PBL heights were derived from the signal-to-noise ratio measured by radar wind profilers, which is sensitive to refractive index variations at the top of the PBL (Wyngaard and LeMone 1980; Angevine et al. 1994; Grimsdell and Angevine 1998).

Different methods are used in the three PBL schemes to determine the PBL height. The MYJ scheme determines the PBL height using the TKE profile. Since the TKE is largest within the PBL, MYJ defines the top of the PBL to be the height where the TKE decreases to a prescribed low value (Janjic 2001). The ACM2 scheme defines the top of the PBL as the height where the bulk Richardson number calculated above the level of neutral buoyancy first exceeds a critical Richardson number (Pleim 2007a). The YSU scheme also uses the bulk Richardson number to define the top of the PBL; however, the bulk Richardson number is calculated starting from the surface (Hong et al. 2006). These different techniques may cause differences in diagnosed PBL heights even if the simulations otherwise matched exactly (Seibert et al. 2000). For a common means of comparison, the simulated PBL heights calculated using the 1.5-theta-increase method (Nielsen-Gammon et al. 2008) are also shown in Fig. 7. The 1.5-theta-increase method defines PBL heights as the level at which the potential temperature first exceeds the minimum potential temperature within the boundary layer by $1.5 \mathrm{~K}$. When applied to observed temperatures, this method has been shown to produce PBL-height estimates that are unbiased relative to profiler-based estimates (NielsenGammon et al. 2008).

\footnotetext{
${ }^{2}$ While the entrainment layer is normally considered part of the convective PBL, we use the term "PBL height" here in a manner consistent with the WRF parameterizations and their output: the height of the top of the layer within which vigorous vertical mixing is taking place, otherwise known as "mixing height."
} 

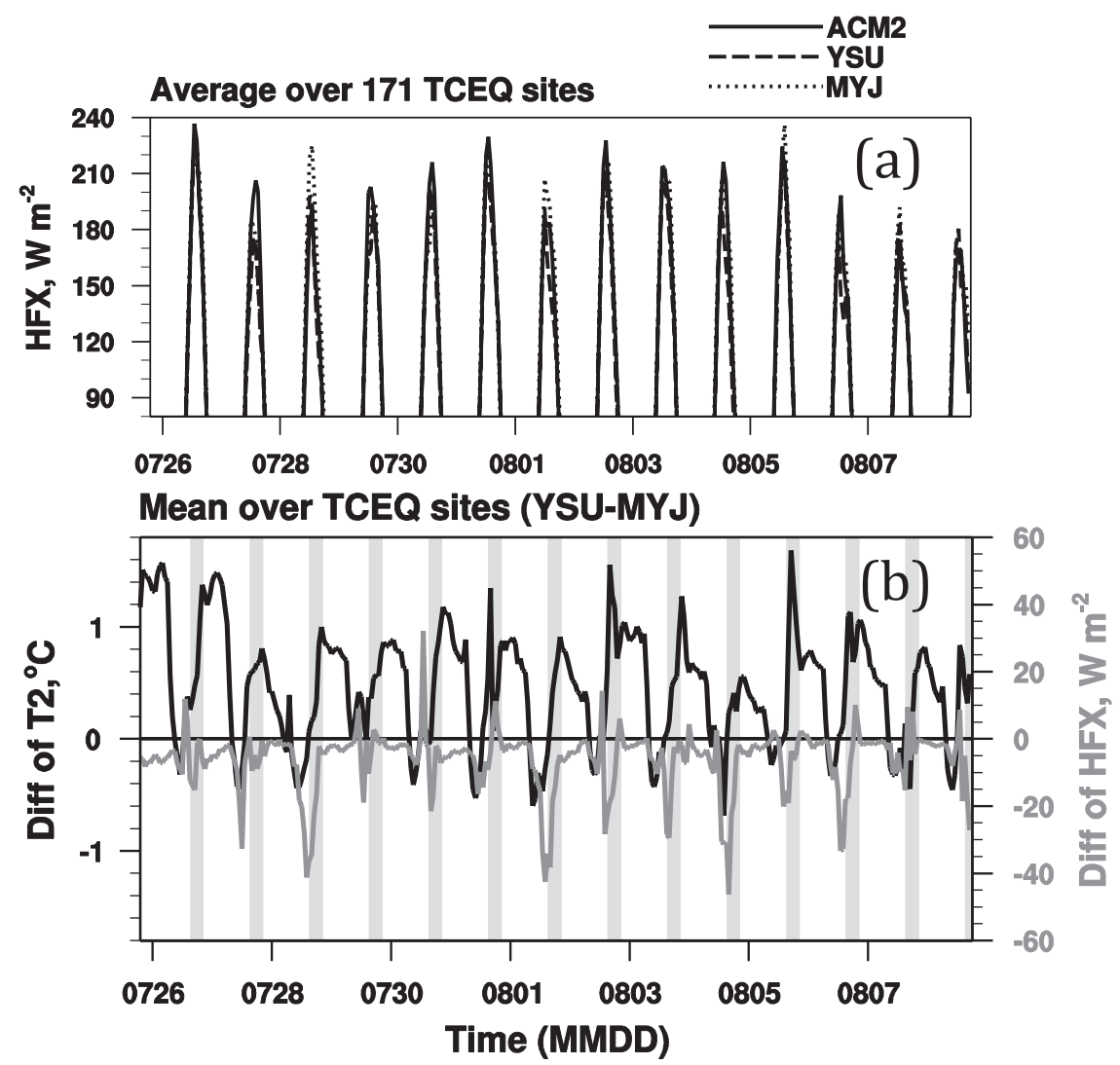

FIG. 6. (a) Mean time series of HFX at 171 TCEQ sites for 26 Jul-8 Aug and (b) difference of 2-m temperature and HFX at TCEQ sites between simulations with the YSU and MYJ schemes at the same time. The time period of 1500-2000 CST in each day is shaded.

The original model-diagnosed PBL heights and the diagnosed PBL heights using the 1.5-theta-increase method are similar for YSU and ACM2 but differ substantially for MYJ. The 1.5-theta-increase method gives higher PBL heights in the afternoon than original modeldiagnosed values for MYJ over all the sites except Sonora (SNR), suggesting that the value of TKE defining the top of the PBL in MYJ (Janjic 2001) may be too large, resulting in artificially low PBL height estimates from MYJ.

Both model and observations show that the PBL over the sites to the west are deeper than those over the sites to the east. This is consistent with climatological precipitation gradients and land surface characteristics. Eastern Texas has more forest, while western Texas is mostly drier rangeland. A similar mixing height pattern is also reported in Wilczak et al. (2009). Among the three PBL schemes, ACM2 predicts the highest PBL height and MYJ predicts the lowest PBL height during daytime on average, even as diagnosed with the 1.5theta-increase method. The PBL heights predicted by YSU are slightly lower than those predicted by ACM2.
The observed PBL heights at all sites increase after sunrise and reach a maximum around 1600 CST. The initial rising trend of PBL heights is captured well by ACM2 and YSU well at most sites but is too rapid at Cleburne (CLE), Jefferson County airport (JFC), and LaPorte (LPT). The modeled PBL heights peak 1-3 h before the observed mixing heights at New Braunfels (NBF), JFC, and Longview (LVW). Overall, the PBL heights modeled with the MYJ scheme peak earliest and are underestimated, except that the 1.5-theta-increase MYJ PBL heights match well with the observed heights at JFC and LPT. The lower PBL heights predicted with the MYJ scheme by all metrics suggest less entrainment of free-tropospheric air into the PBL.

The most direct way to investigate entrainment processes on PBL development is by inspecting of the temperature and moisture profiles. Temperature observations made with commercial aircraft in the DallasFort Worth (DFW) area through the course of the day can be used to evaluate the model-predicted temperature profile. Figure 8 shows mean profiles of temperature and moisture over DFW at three representative 

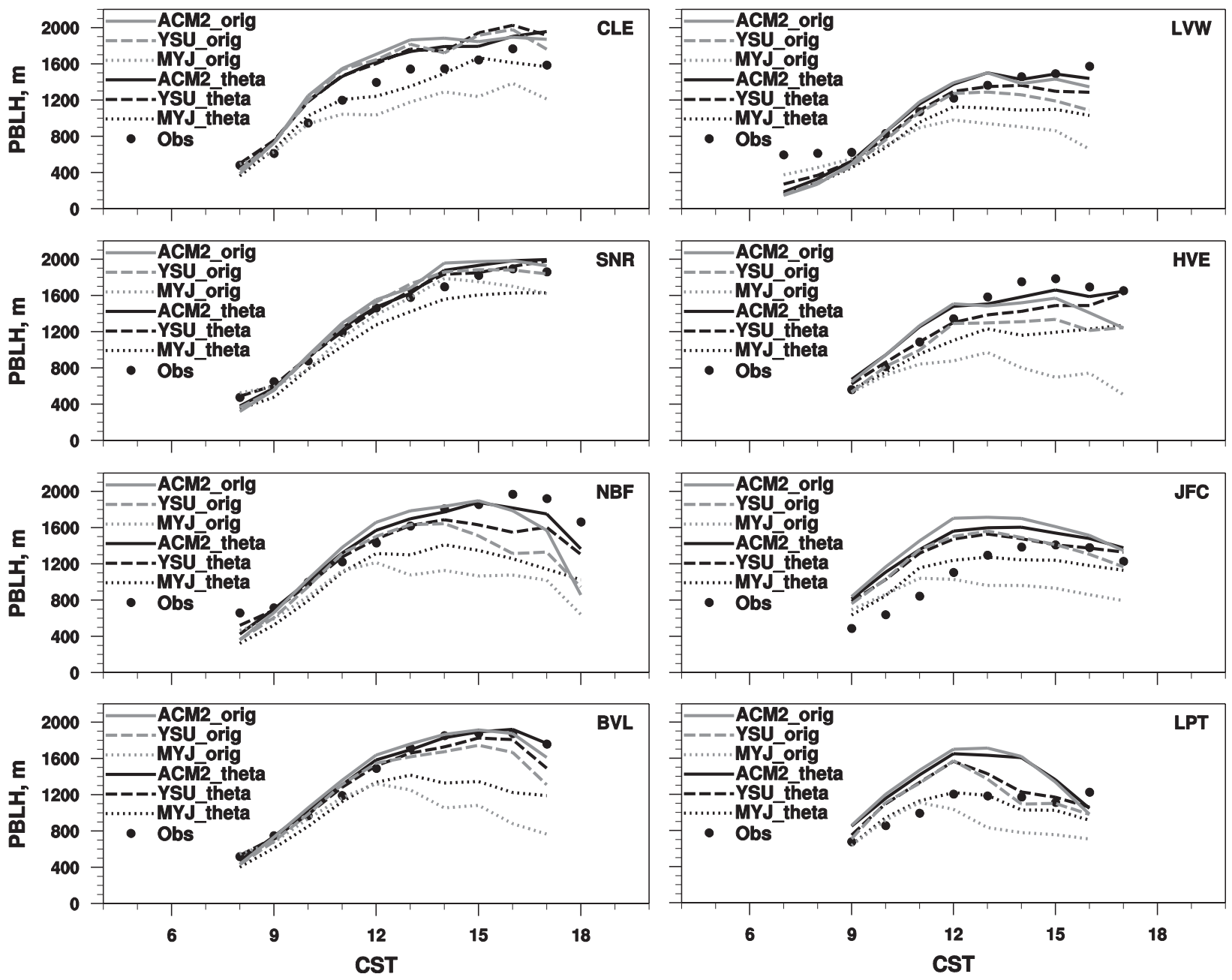

FIG. 7. PBL heights simulated [both model-diagnosed (tagged with_orig) and 1.5-theta-increase method diagnosed (tagged with_theta)] using three PBL schemes (ACM2, YSU, and MYJ) and observed at CLE, LVW, Sonora (SNR), HVE, NBF, JFC, Beeville (BVL), and LPT. The profiler sites are oriented according to geographic location, with CLE farthest to the northwest, and LPT farthest to the southeast. The period of 23-25 Sep is excluded because of the influence of Hurricane Rita.

hours: 0300, 0900, and 1500 CST. The observed mean temperature profiles are shown for comparison. Simulations using all three parameterizations predict lower temperatures than are observed in the lower to middle troposphere, implying some source of error common to all model runs, such as excessive surface moisture availability or incorrect urban land surface characteristics.

While the three model simulations have similar overall values of vertically integrated potential temperature and moisture, important differences are present in the vertical structure. For example, the MYJ runs predict lower temperature and more moisture at 1500 CST than the other runs below $1200 \mathrm{~m}$ and predict higher temperature and less moisture above. Similar differences occur within a shallower layer at $0900 \mathrm{CST}$. This implies that, while similar amounts of heat and moisture are entering the atmosphere from below, the MYJ lacks sufficient heat and moisture transport to entrain warmer and drier air into the PBL, compared to the YSU and ACM2 schemes. This is consistent with the one-dimensional model results of Holtslag et al. (1995) and three-dimensional model results of Hong and Pan (1996) and Srinivas et al. (2007), all of which showed that a nonlocal scheme transports more moisture away from the surface and deposits the moisture at a higher level. To overcome the shortcoming of too weak vertical mixing of the MYJ scheme, attempts have been made to improve the MYJ scheme (e.g., Nakanishi and Niino 2004, 2009). The stronger vertical mixing with the YSU and ACM2 schemes lead to a warmer PBL at 1500 CST, but simulated temperatures are still lower than observed. Investigating the cause of the remaining temperature bias is beyond the scope of this study. 

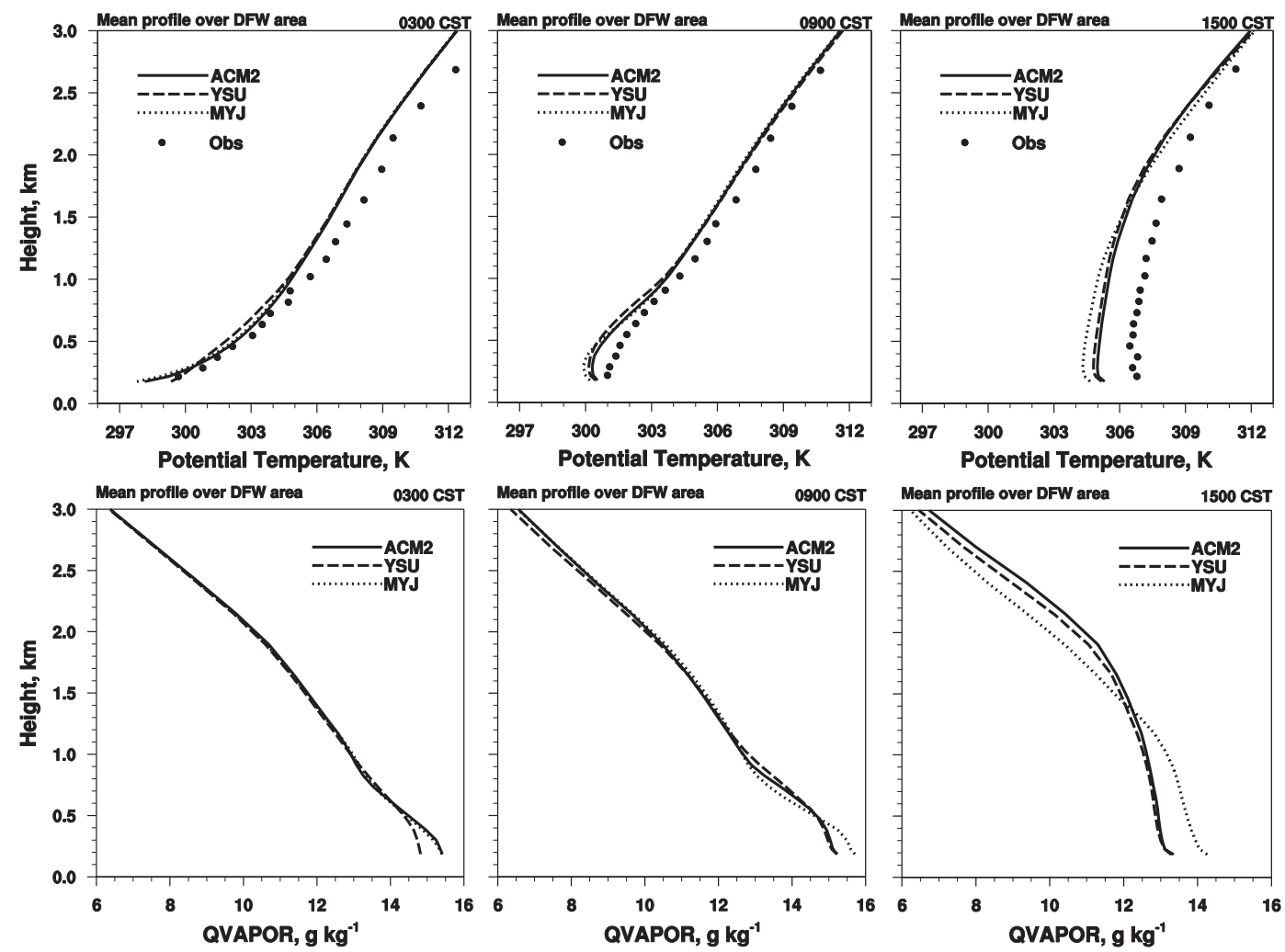

FIG. 8. Mean profiles of (top) temperature and (bottom) moisture at (left to right) 0300, 0900, and 1500 CST. The period of 23-25 Sep is excluded because of the influence of Hurricane Rita.

Figure 9 shows the observed and simulated potential temperature changes from 0900 to $1100 \mathrm{CST}$ at DFW. There is a layer above $1000 \mathrm{~m}$ where potential temperature has fallen by 1100 CST in both simulations and observations because of the entrainment process. As the PBL grows, downward heat fluxes from the formerly free troposphere into the top of the PBL produce a net cooling within the entrainment zone. At 1100 CST, runs with ACM2 and YSU predict similar potential temperature decreases as observed between 1300 and $1900 \mathrm{~m}$, while runs with MYJ predict a smaller potential temperature decrease because of underestimation of the entrainment. The rate of heat content change in the portion of the column with a drop in potential temperature between 0900 and 1100 CST predicted with the YSU scheme is $-52 \mathrm{~W} \mathrm{~m}^{-2}, 2.6$ times as large as that predicted with the MYJ scheme $\left(-20 \mathrm{~W} \mathrm{~m}^{-2}\right)$. This difference accounts for $86 \%$ of the difference of heat content change in the atmosphere below the entrainment zone. Thus, most of the potential temperature difference within the PBL between simulations using MYJ and YSU is attributable to the difference in the downward flux of heat from above the PBL.

Insufficient entrainment flux under convective conditions by the Mellor-Yamada level 2.5 scheme and other local closure schemes has been found in some onedimensional tests (Holtslag et al. 1995; Ayotte et al. 1996; Pagowski 2004). Simulated PBL growth and structure have been shown to be sensitive to the entrainment flux by Ayotte et al. (1996), Betts et al. (1997), and Noh et al. (2003). The nonlocal ACM2 and YSU schemes both were designed for their entrainment flux to better match results from large-eddy simulations. ACM2 does not treat entrainment flux explicitly, but combines a transilient term with local mixing based upon the maximum of two forms of eddy diffusivity $K_{z}$ (i.e., a PBL scaling form of $K_{z}$ discussed in section 4 and a local formulation of $K_{z}$; Pleim 2007b). In the YSU scheme, the entrainment flux is formulated as -0.15 times the surface flux of buoyancy $\overline{\left(w^{\prime} \theta_{h}^{\prime}\right.}=-0.15 \overline{w^{\prime} \theta_{0}^{\prime}}$; Noh et al. 2003; Hong et al. 2006). The true ratio of the entrainment heat flux to the surface buoyancy flux $\left(A_{R}\right)$ is highly variable depending on parameters such as presence of cloud, surface Bowen ratio, wind speed, and so on (Betts 1992; Holtslag et al. 1995; Betts and Barr 1996; Barr and Betts 1997; Margulis and Entekhabi 2004; Angevine 2008; Sorbjan 2009).

After sunset, the temperature and moisture profiles predicted with ACM2 become closer to those predicted with MYJ (see the profiles at 0300 CST; Fig. 8, left). Both of them produce greater static stability near the 


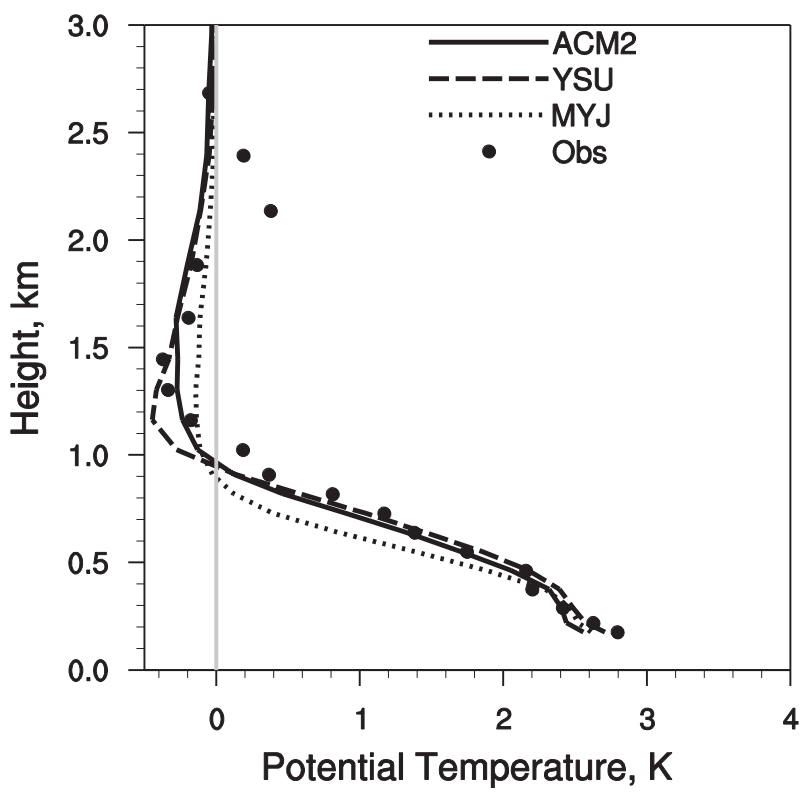

FIG. 9. Mean temperature profile change from 0900 to 1100 CST: simulated (lines) and observed (dots). The period of 23-25 Sep is excluded because of the influence of Hurricane Rita.

surface than with YSU. Under nighttime stable conditions, nonlocal transport is shut down in ACM2 and vertical mixing is purely due to local eddy diffusion as in MYJ. Similar moisture and temperatures at night suggest that ACM2 and MYJ have similar magnitudes of local mixing and both seem to lead to lower surface temperatures than observed (see Fig. 2a). On the other hand, the recent enhancement of nighttime vertical mixing in YSU (Hong and Kim 2008) has contributed to a stronger downward thermal flux and upward moisture flux in the lower atmosphere. This has led to higher temperatures and lower moisture in the simulations with the YSU scheme near the surface at nighttime, in better agreement with observations.

Implementations of realistic nighttime turbulent mixing remain challenging because of the intermittent nature of nighttime turbulence. Some stable boundary layer (SBL) treatments implemented in numerical models result in an unrealistic cold bias near the surface (Derbyshire 1999). Many parameterizations, to circumvent this problem, increase turbulent mixing in the SBL above what would be expected from steady-state turbulence theory (Beljaars and Holtslag 1991; Viterbo et al. 1999; Van de Wiel et al. 2002; Steeneveld et al. 2006). Likewise, the increase of nighttime mixing in YSU in WRF version 3 seems to have improved its representation of nighttime conditions.

In addition to differences in thermodynamic scalars, the model simulations with the various PBL schemes produce some systematic differences in the vertical profiles of wind speed, while the diurnal variations of wind speed are similar among the simulations. Figure 10 shows simulated and observed 3-month mean wind speed profiles at LPT, Huntsville (HVE), and LVW at 0600 CST (when the lowest surface wind speed occurs) and 1500 CST (when the highest surface wind speed occurs). Among the three sites, LaPorte is closest to the Gulf of Mexico and Longview is farthest. The lowest profiler data levels at LaPorte, Huntsville, and Longview are 136, 224, and $229 \mathrm{~m}$, respectively.

During daytime, runs with YSU and ACM2 produce less bias in wind speed profiles in the PBL, with lower wind speeds than runs with MYJ. The MYJ scheme is also reported in Zhang and Zheng (2004) to lead to higher predicted wind speeds near the ground at 1300 CST than several other PBL schemes. Such systematic differences of wind speeds in the PBL may have important implications for the simulated horizontal dispersion of pollutants in air quality modeling.

During nighttime, since eddy viscosity declines near the surface, all the schemes tend to produce large lowlevel wind shear. Wind speeds increase with height rapidly in the lowest $200 \mathrm{~m}$ and a low-level jet (LLJ) develops over all sites with all parameterizations (except over LaPorte with YSU). The wind speed predicted with MYJ and ACM2 increases more rapidly in the lowest $200 \mathrm{~m}$ than that predicted by YSU, resulting in stronger LLJs. This implies that the nighttime vertical mixing of momentum near the surface predicted with MYJ and ACM2 is weaker than that predicted with YSU. Zhang and Zheng (2004) also reported that the MYJ scheme led to a stronger LLJ during nighttime than most other tested schemes. The nighttime wind speed variations are consistent with the earlier diagnosis, based on thermodynamic considerations, of less nighttime mixing with MYJ and ACM2 than with YSU.

\section{Simulations with ACM2 with different mixing strength}

The primary cause of differences in PBL structure was diagnosed above as differences in vertical mixing strength and entrainment flux predicted by the PBL schemes. To further explore this issue, experiments that alter vertical mixing strength and entrainment flux are reported in this section.

In the MYJ scheme, the vertical mixing coefficients depend on the master length scale and TKE. The calculation of the master length scale in the PBL involves the integration of TKE within the PBL. TKE is computed from the TKE equation with shear, buoyancy production, and dissipation terms, which in turn involve the master length scale. Thus in the MYJ scheme, the whole equation system is strongly coupled, which makes 

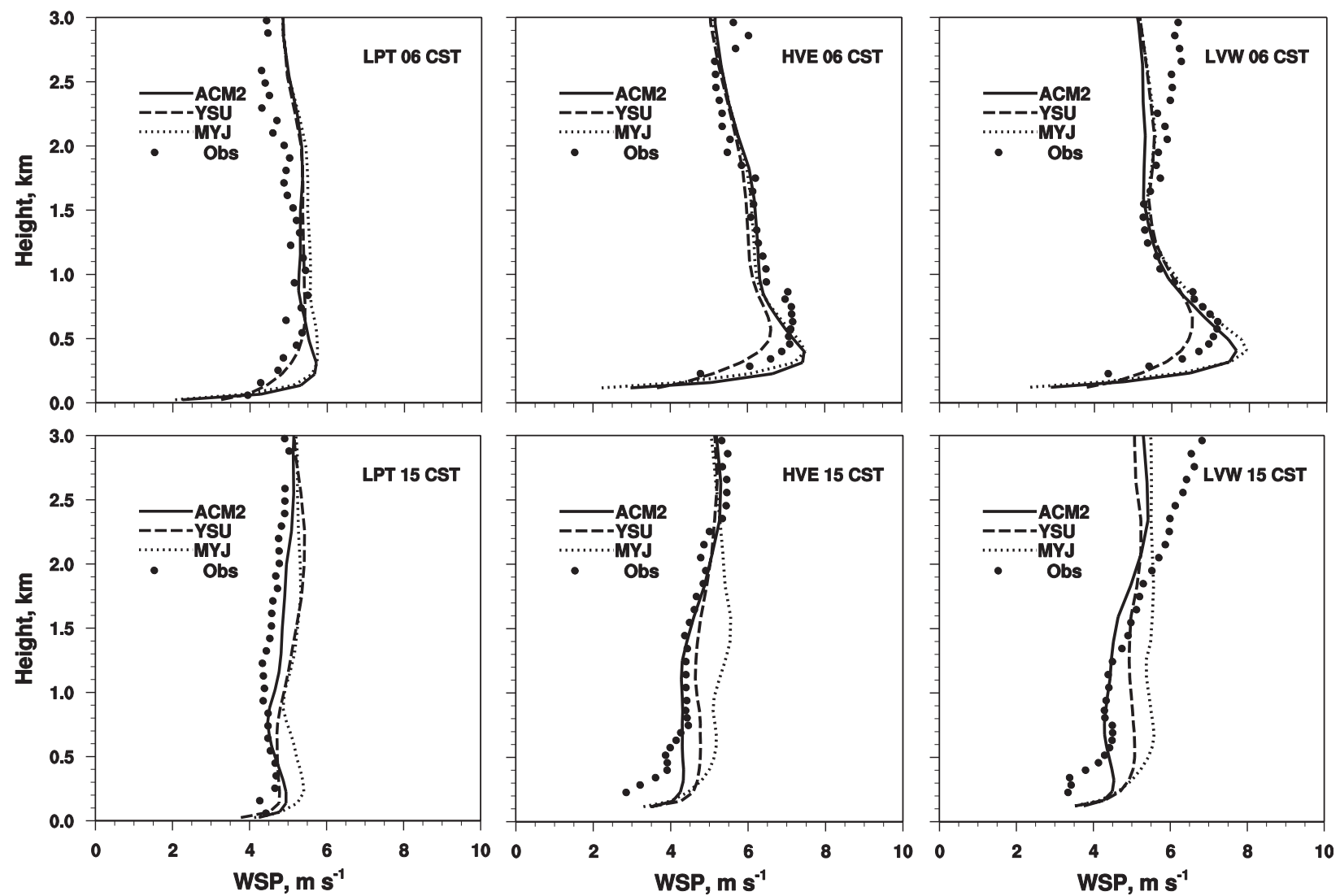

FIG. 10. Simulated and observed 3-month mean wind speed (WSP) profiles at (left) LPT, (center) HVE, and (right) LVW at (top) 0600 and (bottom) 1500 CST. The period of 23-25 Sep is excluded because of the influence of Hurricane Rita.

it difficult to increase or decrease the vertical mixing strength without modifying the equation system substantially. On the other hand, the local vertical diffusivity in ACM2 and YSU is computed from

$$
K_{z}(z)=k \frac{u_{*}}{\phi} z(1-z / h)^{p}
$$

In ACM2, the value of the exponent $p$ in (1) is 2 , but values ranging from 1 to 3 have been considered (Troen and Mahrt 1986). Figure 11 shows the normalized $K_{z}$ profile corresponding to five different $p$ values within this range, with the PBL height set at $2000 \mathrm{~m} ; K_{z}$ varies considerably when $p$ varies between 1 and 3 . Thus $p$ plays an important role in governing the vertical mixing strength in the daytime PBL in ACM2.

Five short-term simulations are conducted for the period of 0000 UTC 30 August-0000 UTC 1 September 2006 with the WRF model with ACM2 modified to use the five different $p$ values depicted in Fig. 11. Figure 12 shows the mean profile of potential temperature and water vapor mixing ratio over the 211 NWS-FAA sites at 1300 CST, 30 August 2006, a time of day when sensitivity to $p$ is large (Nielsen-Gammon et al. 2010). Notice that different mixing strengths lead to similar patterns of variations in temperature and moisture as were seen in Fig. 8 (column 3) with different PBL schemes. With smaller $p$, thus stronger local vertical mixing, potential temperature and water vapor mixing ratio are well mixed to a higher level, while larger $p$ leads to a cooler and moister lower PBL and a warmer and drier free troposphere. Such sensitivity is monotonic with respect to $p$. Potential temperature varies by $\sim 0.4^{\circ} \mathrm{C}$ and water vapor mixing ratio varies by $\sim 0.6 \mathrm{~g} \mathrm{~kg}^{-1}$ in the lower PBL over this range of $p$, and the level of the sudden change in stratification at the top of the PBL (diagnosed from Fig. 12) varies by several hundred meters depending on the value of $p$.

As will be reported elsewhere (Nielsen-Gammon et al. 2010), similar sensitivity of WRF with ACM2 (but with smaller magnitude) is found for other parameters in ACM2 that controls the mixing strength in the PBL, such as the critical Richardson number that governs the calculation of PBL height. The similarity between the 


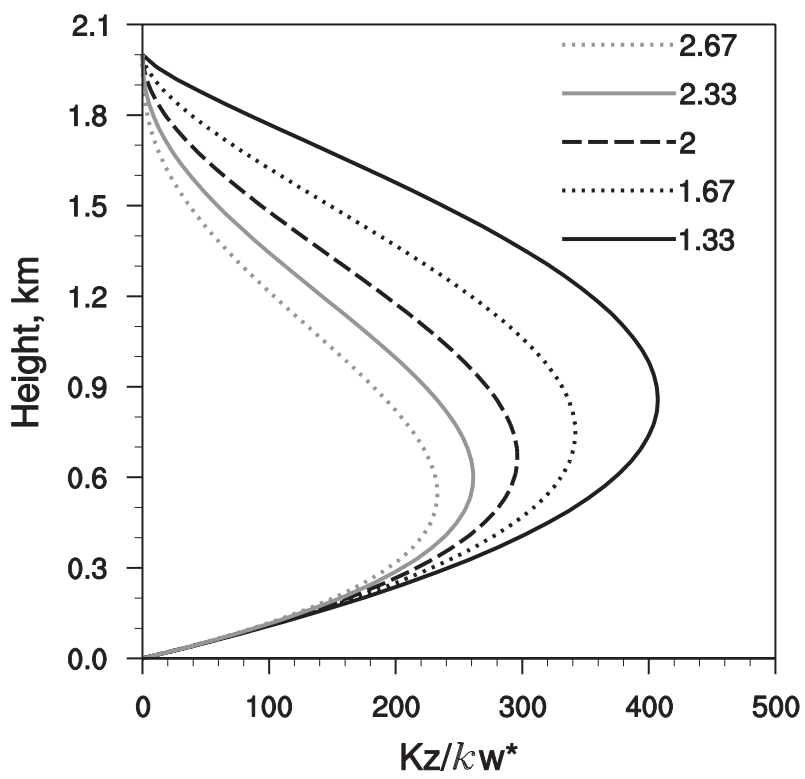

FIG. 11. Normalized $K_{z}$ profiles computed using different values of $p$. The PBL height is set at $2000 \mathrm{~m}$.

sensitivity of WRF with ACM2 to varied local mixing strength and the sensitivity of WRF to different PBL schemes confirms that much of the sensitivity of WRF to different PBL schemes is attributable to their different vertical mixing strengths and different resulting entrainment. In the ACM2 scheme, at least, entrainment is sensitive to the parameterization of mixing within the PBL.

\section{Summary}

A series of simulations spanning three months during summer 2005 is conducted with WRF V3.0.1 with three
PBL schemes (MYJ, YSU, and ACM2) and compared with surface and boundary layer observations in the south-central United States. With the configuration used in this study, the WRF simulations underpredict temperature and overpredict moisture near the surface (except for slightly underestimating nighttime moisture at NWSFAA sites when the YSU scheme is used). Use of the local-closure MYJ scheme produces the largest bias. The YSU and ACM2 schemes both lead to predictions of higher temperature and lower moisture, and thus smaller biases, than the MYJ scheme in the lower atmosphere during daytime because of their stronger vertical mixing. Stronger vertical mixing causes stronger entrainment at the top of PBL, which helps warm and dry the PBL. In the local-closure MYJ scheme, the only entrainment that develops must come from local mixing. Entrainment from penetrating plumes or large eddies is not accounted for. Underestimated entrainment is shown to at least partially cause the colder PBL predicted by the WRF model with the MYJ scheme. Our conclusion is further verified by simulations with altered local vertical mixing strength. Increasing the local vertical mixing in a localclosure PBL scheme may at least partially compensate for the lack of nonlocal vertical mixing. During nighttime the WRF model with the YSU PBL scheme produces higher temperatures and lower moisture than with the other two schemes in the lower atmosphere because of its enhanced mixing during nighttime.

Acknowledgments. This work was supported by the State of Texas through a contract from the Houston Advanced Research Center, Texas Environmental Research Consortium, and the Texas Commission on Environmental Quality. Charley Knoderer and Clinton
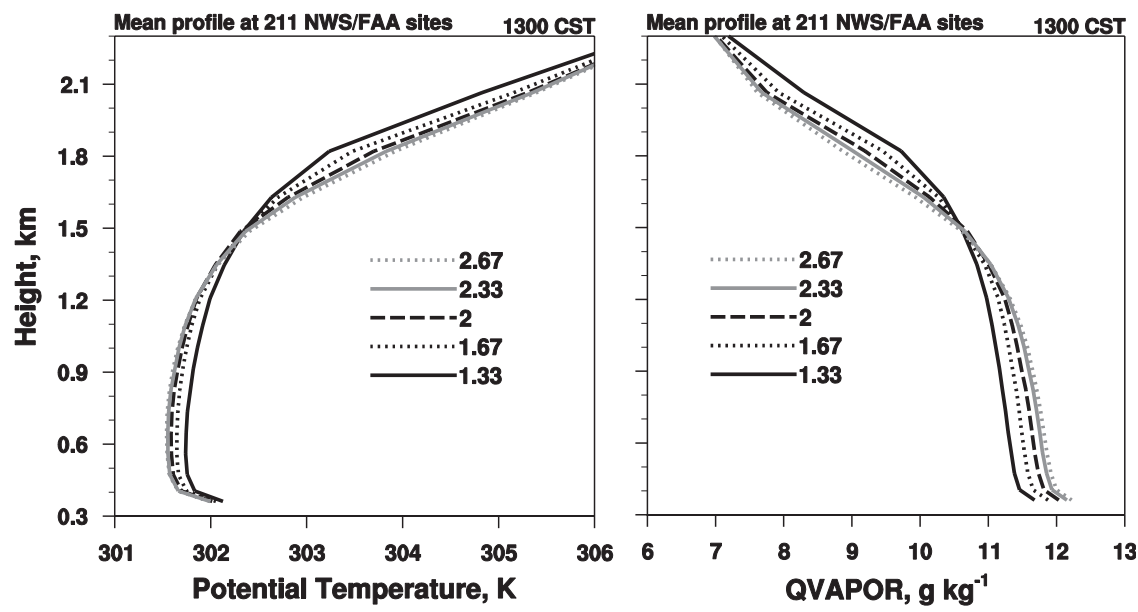

FIG. 12. Mean profiles of (left) potential temperature and (right) water vapor mixing ratio at 1300 CST 30 Aug 2006 from sensitivity runs with ACM2 modified to use different values of $p$. 
MacDonald of Sonoma Technology, Inc., provided the profiler-based mixing height estimates. Discussions with Jon Pleim were helpful for testing the ACM2 scheme.

\section{REFERENCES}

Angevine, W. M., 2008: Transitional, entraining, cloudy, and coastal boundary layers. Acta Geophys., 56 (1), 2-20.

— A. B. White, and S. K. Avery, 1994: Boundary layer depth and entrainment zone characterization with a boundary layer profiler. Bound.-Layer Meteor., 68, 375-385.

Ayotte, K. W., and Coauthors, 1996: An evaluation of neutral and convective planetary boundary-layer parameterizations relative to large eddy simulations. Bound.-Layer Meteor., 79, 131-175.

Banta, R. M., and Coauthors, 2005: A bad air day in Houston. Bull. Amer. Meteor. Soc., 86, 657-669.

Bao, J.-W., S. A. Michelson, S. A. McKeen, and G. A. Grell, 2005: Meteorological evaluation of a weather-chemistry forecasting model using observations from the TEXAS AQS 2000 field experiment. J. Geophys. Res., 110, D21105, doi:10.1029/ 2004JD005024.

Barr, A. G., and A. K. Betts, 1997: Radiosonde boundary layer budgets above a boreal forest. J. Geophys. Res., 102D, 29205 29212.

Beljaars, A. C. M., and A. A. M. Holtslag, 1991: Flux parameterization over land surfaces for atmospheric models. J. Appl. Meteor., 30, 327-341.

Betts, A. K., 1992: FIFE atmospheric boundary layer budget methods. J. Geophys. Res., 97D, 18 523-18 532.

_ , and A. G. Barr, 1996: FIFE 1987 sonde budget revisited. J. Geophys. Res., 101, 23 285-23 288.

_ , F. Chen, K. E. Mitchell, and Z. I. Janjic, 1997: Assessment of the land surface and boundary layer models in two operational versions of the NCEP Eta model using FIFE data. Mon. Wea. Rev., 125, 2896-2916.

Blackadar, A. K., 1978: Modeling pollutant transfer during daytime convection. Preprints, Fourth Symp. on Atmospheric Turbulence, Diffusion, and Air Quality, Reno, NV, Amer. Meteor. Soc., 443-447.

Borge, R., V. Alexandrov, J. J. del Vas, J. Lumbreras, and E. Rodriguez, 2008: A comprehensive sensitivity analysis of the WRF model for air quality applications over the Iberian Peninsula. Atmos. Environ., 42, 8560-8574.

Braun, S. A., and W.-K. Tao, 2000: Sensitivity of high-resolution simulations of Hurricane Bob (1991) to planetary boundary layer parameterizations. Mon. Wea. Rev., 128, 39413961.

Bright, D. R., and S. L. Mullen, 2002: The sensitivity of the numerical simulation of the southwest monsoon boundary layer to the choice of PBL turbulence parameterization in MM5. Wea. Forecasting, 17, 99-114.

Brown, A. R., 1996: Evaluation of parameterization schemes for the convective boundary layer using large-eddy simulation results. Bound.-Layer Meteor., 81, 167-200.

Chen, F., and J. Dudhia, 2001: Coupling an Advanced Land SurfaceHydrology Model with the Penn State-NCAR MM5 Modeling System. Part I: Model implementation and sensitivity. Mon Wea. Rev., 129, 569-585.

Dabberdt, W. F., and Coauthors, 2004: Meteorological research needs for improved air quality forecasting: Report of the 11th Prospectus Development Team of the U.S. Weather Research Program. Bull. Amer. Meteor. Soc., 85, 563-586.
Daum, P. H., L. I. Kleinman, S. R. Springston, L. J. Nunnermacker, Y.-N. Lee, J. Weinstein-Lloyd, J. Zheng, and C. M. Berkowitz, 2003: A comparative study of $\mathrm{O}_{3}$ formation in the Houston urban and industrial plumes during the 2000 Texas Air Quality Study. J. Geophys. Res., 108 (D23), 4715, doi:10.1029/ 2003JD003552.

Derbyshire, S. H., 1999: Boundary-layer decoupling over cold surfaces as a physical boundary instability. Bound.-Layer Meteor., 90, 297-325.

Dudhia, J., 1989: Numerical study of convection observed during the winter monsoon experiment using a mesoscale twodimensional model. J. Atmos. Sci., 46, 3077-3107.

Grell, G. A., and D. Dévényi, 2002: A generalized approach to parameterizing convection combining ensemble and data assimilation techniques. Geophys. Res. Lett., 29, 1693, doi:10.1029/ 2002 GL015311.

Grimsdell, A. W., and W. M. Angevine, 1998: Convective boundary layer height measurement with wind profilers and comparison to cloud base. J. Atmos. Oceanic Technol., 15, 1331-1338.

Han, Z., H. Ueda, and J. An, 2008: Evaluation and intercomparison of meteorological predictions by five MM5-PBL parameterizations in combination with three land-surface models. Atmos. Environ., 42, 233-249.

Holt, T., and S. Raman, 1988: A review and comparative evaluation of multilevel boundary layer parameterizations for first-order and turbulent kinetic energy closure schemes. Rev. Geophys., 26, 761-780

Holtslag, A. A. M., E. van Meijgaard, and W. C. de Rooy, 1995: A comparison of boundary layer diffusion schemes in unstable conditions over land. Bound.-Layer Meteor., 76, 69-95.

Hong, S.-Y., and H.-L. Pan, 1996: Nonlocal boundary layer vertical diffusion in a medium-range forecast model. Mon. Wea. Rev., 124, 2322-2339.

, and S.-W. Kim, 2008: Stable boundary layer mixing in a vertical diffusion scheme. Proc. Ninth Annual WRF User's Workshop, Boulder, CO, National Center for Atmospheric Research, 3.3. [Available online at http://www.mmm.ucar.edu/ wrf/users/workshops/WS2008/abstracts/3-03.pdf.]

— - J. Dudhia, and S.-H. Chen, 2004: A revised approach to icemicrophysical processes for the bulk parameterization of cloud and precipitation. Mon. Wea. Rev., 132, 103-120.

-, Y. Noh, and J. Dudhia, 2006: A new vertical diffusion package with explicit treatment of entrainment processes. Mon. Wea. Rev., 134, 2318-2341.

Janjic, Z. I., 1990: The step-mountain coordinate: Physical package. Mon. Wea. Rev., 118, 1429-1443.

_, 1994: The step-mountain Eta coordinate model: Further developments of the convection, viscous layer, and turbulence closure schemes. Mon. Wea. Rev., 122, 927-945.

, 2001: Nonsingular implementation of the Mellor-Yamada level 2.5 scheme in the NCEP Meso model. NOAA/NWS/ NCEP Office Note 437, $61 \mathrm{pp}$.

Jankov, I., W. A. Gallus Jr., M. Segal, B. Shaw, and S. E. Koch, 2005: The impact of different WRF model physical parameterizations and their interactions on warm season MCS rainfall. Wea. Forecasting, 20, 1048-1060.

, P. J. Schultz, C. J. Anderson, and S. E. Koch, 2007: The impact of different physical parameterizations and their interactions on cold season QPF in the American river basin. J. Hydrometeor., 8, 1141-1151.

Langford, A. O., C. J. Senff, R. M. Banta, R. M. Hardesty, R. J. Alvarez II, S. P. Sandberg, and L. S. Darby, 2009: Regional and local background ozone during Texas Air Quality 
Study 2006. J. Geophys. Res., 114, D00F12, doi:10.1029/ 2008JD011687.

Li, X., and Z. Pu, 2008: Sensitivity of numerical simulation of early rapid intensification of Hurricane Emily (2005) to cloud microphysical and planetary boundary layer parameterizations. Mon. Wea. Rev., 136, 4819-4838.

Leung, L. R., and S. J. Ghan, 1998: Parameterizing subgrid orographic precipitation and surface cover in climate models. Mon. Wea. Rev., 126, 3271-3291.

Margulis, S. A., and D. Entekhabi, 2004: Boundary-layer entrainment estimation through assimilation of radiosonde and micrometeorological data into a mixed layer model. Bound.-Layer Meteor., 110, 405-433.

Mellor, G. L., and T. Yamada, 1982: Development of a turbulence closure model for geophysical fluid problems. Rev. Geophys., 20, 851-875.

Miao, J.-F., and Coauthors, 2008: Evaluation of MM5 mesoscale model at local scale for air quality applications over the Swedish west coast: Influence of PBL and LSM parameterizations. Meteor. Atmos. Phys., 99, 77-103.

Misenis, C., X.-M. Hu, S. Krishnan, Y. Zhang, and J. Fast, 2006: Sensitivity of WRF/Chem predictions to meteorological schemes. Proc. 86th Annual Conference/14th Joint Conf. on the Applications of Air Pollution Meteorology with the A\&WMA, Atlanta, GA, Amer. Meteor. Soc., paper 1.8.

Mlawer, E. J., S. J. Taubman, P. D. Brown, M. J. Iacono, and S. A. Clough, 1997: Radiative transfer for inhomogeneous atmospheres: RRTM, a validated correlated-k model for the longwave. J. Geophys. Res., 102D, 16 663-16 682.

Nakanishi, M., and H. Niino, 2004: An improved Mellor-Yamada level-3 model with condensation physics: Its design and verification. Bound.-Layer Meteor., 112, 1-31.

$\longrightarrow$, and - 2009: Development of an improved turbulence closure model for the atmospheric boundary layer. J. Meteor. Soc. Japan, 87, 895-912.

Nielsen-Gammon, J. W., and Coauthors, 2008: Multisensor estimation of mixing heights over a coastal city. J. Appl. Meteor. Climatol., 47, 27-43.

—, X.-M. Hu, F. Zhang, and J. Pleim, 2010: Evaluation of planetary boundary layer scheme sensitivities for the purpose of parameter estimation. Mon. Wea. Rev., 138, 3400-3417.

Noh, Y., W. G. Cheon, S.-Y. Hong, and S. Raasch, 2003: Improvement of the K-profile model for the planetary boundary layer based on large eddy simulation data. Bound.-Layer Meteor., 107, 401-427.

Pagowski, M., 2004: Some comments on PBL parameterizations in WRF. Proc. Joint WRF/MM5 Users' Workshop, Boulder, CO, National Center for Atmospheric Research, 1.13. [Available online at http://www.mmm.ucar.edu/mm5/workshop/ws04/ Session1/Pagowski.Mariusz_web.pdf.]

Parrish, D. D., and Coauthors, 2009: Overview of the Second Texas Air Quality Study (TexAQS II) and the Gulf of Mexico Atmospheric Composition and Climate Study (GoMACCS). J. Geophys. Res., 114, D00F13, doi:10.1029/2009JD011842.

Pleim, J. E., 2007a: A combined local and nonlocal closure model for the atmospheric boundary layer. Part I: Model description and testing. J. Appl. Meteor. Climatol., 46, 1383-1395.

- 2007b: A combined local and nonlocal closure model for the atmospheric boundary layer. Part II: Application and evaluation in a mesoscale meteorological model. J. Appl. Meteor. Climatol., 46, 1396-1409.

_ mixing in the convective boundary layer. Atmos. Environ., 26A, 965-981.

Seibert, P., F. Beyrich, S.-E. Gryning, S. Joffre, A. Rasmussen, and P. Tercier, 2000: Review and intercomparison of operational methods for the determination of the mixing height. Atmos. Environ., 34, 1001-1027.

Skamarock, W. C., and Coauthors, 2008: A description of the advanced research WRF version 3. NCAR Tech. Note TN475_STR, 113 pp.

Sorbjan, Z., 2009: Improving non-local parameterization of the convective boundary layer. Bound.-Layer Meteor., 130 (1), $57-69$.

Srinivas, C. V., R. Venkatesan, and A. Bagavath Singh, 2007: Sensitivity of mesoscale simulations of land-sea breeze to boundary layer turbulence parameterization. Atmos. Environ., 41, 2534-2548.

Steeneveld, G. J., B. J. H. van de Wiel, and A. A. M. Holtslag, 2006: Modeling the arctic stable boundary layer and its coupling to the surface. Bound.-Layer Meteor., 118, 357-378.

Stull, R. B., 1984: Transilient turbulence theory. Part I: The concept of eddy-mixing across finite distances. J. Atmos. Sci., 41, 3351-3367.

Troen, I., and L. Mahrt, 1986: A simple model of the atmospheric boundary layer: Sensitivity to surface evaporation. Bound.Layer Meteor., 37, 129-148.

Van de Wiel, B. J. H., R. J. Ronda, A. F. Moene, H. A. R. De Bruin, and A. A. M. Holtslag, 2002: Intermittent turbulence and oscillations in the stable boundary layer over land. Part I: A bulk model. J. Atmos. Sci., 59, 942-958.

Viterbo, P., A. Beljaars, J. F. Mauhoff, and J. Teixeira, 1999: The representation of soil moisture freezing and its impact on the SBL. Quart. J. Roy. Meteor. Soc., 125, 2401-2426.

Wilczak, J. M., and Coauthors, 2009: Analysis of regional meteorology and surface ozone during the TexAQS II Field Program and an evaluation of the NMM-CMAQ and WRF-Chem air quality models. J. Geophys. Res., 114, D00F14, doi:10.1029/ 2008JD011675.

Wyngaard, J. C., and M. A. LeMone, 1980: Behavior of the refractive index structure parameter in the entraining convective boundary layer. J. Atmos. Sci., 37, 1573-1585.

Zhang, D.-L., and R. A. Anthes, 1982: A high-resolution model of the planetary boundary layer-Sensitivity tests and comparisons with SESAME-79 data. J. Appl. Meteor., 21, 15941609.

— , and W.-Z. Zheng, 2004: Diurnal cycles of surface winds and temperatures as simulated by five boundary layer parameterizations. J. Appl. Meteor., 43, 157-169.

Zhang, F., N. Bei, J. W. Nielsen-Gammon, G. Li, R. Zhang, A. Stuart, and A. Aksoy, 2007: Impacts of meteorological uncertainties on ozone pollution predictability estimated through meteorological and photochemical ensemble forecasts. J. Geophys. Res., 112, D04304, doi:10.1029/2006JD007429.

Zhong, S., H. In, and C. Clements, 2007: Impact of turbulence, land surface, and radiation parameterizations on simulated boundary layer properties in a coastal environment. J. Geophys. Res., 112, D13110, doi:10.1029/2006JD008274. 